\title{
Reducing the burden of lower respiratory tract infections in infants in the Canadian Arctic
}

\author{
Ian Mitchell MA MB, Delshani Peiris MIPH
}

Cite as: CMAJ 2017 March 27;189:E450-1. doi: 10.1503/cmaj.161293

See related CMAJ Open articles at www.cmajopen.ca/content/4/4/E615 and www.cmajopen.ca/content/4/4/E623

$\mathbf{T}$ o reduce the prevalence of lower respiratory tract infection in infants in the Canadian Arctic requires specific medical measures; but medical measures alone are insufficient. Only by also addressing the social determinants of health experienced in the region will we see a lasting effect on the health of these infants. In addition, we recommend routine surveillance of lower respiratory tract infections in infants in Canada to track the frequency and progress of infections and to identify emerging pathogens in at-risk populations.

In recent CMAJ Open research articles, ${ }^{1,2}$ Banerji and colleagues focus on infants in Arctic Canada and confirm the importance of lower respiratory tract infection in infancy as a driver of health care costs, something true for all communities. The authors highlight the burden experienced by infants and their families in northern Canada, given the difficulty and inconvenience of long travel distances for medical assessment and hospital care. Of the 348 admissions for lower respiratory tract infection among 293 infants in their study, 66 were to tertiary care centres in southern Canada, which further increased the burden on families and costs to the health care system. ${ }^{1}$ In addition, one infant died in transit. As in all such studies, respiratory syncytial virus was the single most common pathogen, found in 124 cases ( $41.6 \%$ of those tested), alone or as coinfection. The evidence in these studies and additional literature is that respiratory syncytial virus and influenza $A$ are the most important pathogens, and ones for which we have preventive measures.

The Public Health Agency of Canada specifically recommends influenza vaccination for children aged 6-59 months and for Indigenous people because both groups are at high risk of influenza-related complications or hospital admission. ${ }^{3}$ Infants and children in the Indigenous population experience disproportionate morbidity from infectious disease, often because of overcrowded living conditions. Therefore, influenza vaccination should be as close to universal as possible to limit infection. But effective prevention of lower respiratory tract infection in infancy requires more than this specific preventive measure. Prevention of respiratory syncytial virus infection might be helped to some extent by nonspecific measures such as rigorous handwashing.

\section{KEY POINTS}

- There is a high prevalence of lower respiratory tract infection among infants in the Canadian Arctic, especially in Nunavut.

- The burden of disease on Indigenous infants and their families in northern communities, and on health care systems, is influenced by social determinants of health.

- Reducing the prevalence of lower respiratory tract infection requires specific action, such as increasing influenza vaccination coverage in northern Canada and widening the use of palivizumab prophylaxis in some healthy term infants.

- To improve health outcomes in northern Canada, social determinants of health must be addressed, specifically overcrowded housing, food security and access to health services.

However, in the absence of active immunization, more widespread use of monoclonal antibody palivizumab should be considered.

There is no vaccine for respiratory syncytial virus. This was the pathogen most associated with severe lower respiratory tract infection (defined as requiring mechanical ventilation or cardiopulmonary resuscitation, or death) in the study by Banerji and colleagues. ${ }^{1}$ This raises the question of whether palivizumab can reduce sequelae in populations with such severe consequences of this virus. In their cost-effectiveness analysis, Banerji and colleagues focus on palivizumab prophylaxis of respiratory syncytial virus infection. ${ }^{2}$ Randomized placebo-controlled studies have shown the drug to be effective in preterm infants and infants with chronic lung disease ${ }^{4}$ and in those with hemodynamically important congenital heart disease. ${ }^{5}$ Some evidence of palivizumab's benefit has been reported in groups of infants in Canada, but it was not from a randomized placebo-controlled trial. ${ }^{6}$ Challenges in administering the drug relate to the strict four-week injection intervals and the need to recalculate the dose at each visit, which are magnified in northern Canada. These challenges and concerns of cost have led to palivizumab being recommended in high-risk populations only. 
A recent position statement on the use of palivizumab from the Canadian Paediatric Society ${ }^{7}$ led to immediate expression of concern of the major focus on cost. ${ }^{8}$ In relation to remote communities, the statement says "[c]onsideration may be given to administering palivizumab during [respiratory syncytial virus] season to term Inuit infants until they reach six months of age only if they live in communities with documented persistent high rates of [respiratory syncytial virus] hospitalization." The statement is qualified by emphasizing that "the first priority should be to provide palivizumab to infants with prematurity, [chronic lung disease] or [congenital heart disease]," without giving details of prioritization. ${ }^{7}$ Palivizumab is currently being used in Indigenous and northern communities, but with problems in adherence. ${ }^{9}$

One striking finding in the surveillance study by Banerji and colleagues $^{1}$ were lower rates of hospital admission reported in Yellowknife (39 per 1000 live births) compared with Nunavik (456 per 1000 live births). ${ }^{1}$ Lest we feel complacent about Yellowknife, the authors note that the rates reported are at the high end of those seen in the United States. Variations in rates of admission for lower respiratory tract infection between institutions are common, mainly owing to variation in physician practice. ${ }^{10}$ Both studies by Banerji and colleagues suggest a partial explanation that the marked difference in rates between Northwest Territories and Nunavut may be caused by a genetic predisposition in Inuit to severe disease. The authors also suggest that variation in admission rates are aggravated by social determinants of health. Social determinants of health contribute to disease prevalence more than variation in physician practice.

Targeted interventions, such as specific guidelines for palivizumab treatment, are necessary but insufficient. More general interventions aimed at mitigating the effects of social determinants of health will address a magnitude of health issues. The health status of Indigenous peoples in northern communities is attributed specifically to overcrowding due to housing shortages and the need for equitable access to health services. Geographic limitations and isolation will make it difficult to reorient health services to increase access. Banerji and colleagues outline strong and independent risk factors for lower respiratory tract infection, including smoking during pregnancy and lack of breastfeeding. Health interventions that address risk factors such as these can increase the overall health of mothers and infants, making them less susceptible to disease. Further, social interventions to address overcrowded housing with poor ventilation and food security can help to reduce the transmission of infectious disease and the burden of lower respiratory illness on Indigenous infants. They can also help to improve the overall health of the population through better nutrition and quality of life.

The National Collaborating Centre for Aboriginal Health describes Canada's health policy for Indigenous peoples as "patchwork" legislation. ${ }^{11}$ Responsibility differs from federal, provincial/territorial and Indigenous governments throughout the country, which creates confusion in the provision of health services. Commitment to monitoring health services and programs is necessary everywhere, but especially in remote Indigenous communities, where gaps in health coverage are far too common. Indigenous infants in northern communities are at a marked health disadvantage. Coordinated effort is required by federal, territorial and local governments to address health inequities and increase access to health care in the Canadian Arctic.

\section{References}

1. Banerji A, Panzov V, Young M, et al. Hospital admissions for lower respiratory tract infections among infants in the Canadian Arctic: a cohort study. CMAJ Open 2016;4:E615-22.

2. Banerji A, Ng K, Moraes TJ, et al. Cost-effectiveness of palivizumab compared to no prophylaxis in term infants residing in the Canadian Arctic. CMAJ Open 2016;4:E623-33.

3. Canadian immunization guide chapter on influenza and statement on seasonal influenza vaccine for 2016-2017. Ottawa: Public Health Agency of Canada; 2016.

4. Palivizumab, a humanized respiratory syncytial virus monoclonal antibody, reduces hospitalization from respiratory syncytial virus infection in high-risk infants. The IMpact RSV Study Group. Pediatrics 1998;102:531-7.

5. Feltes TF, Cabalka AK, Meissner HC, et al. Palivizumab prophylaxis reduces hospitalization due to respiratory syncytial virus in young children with hemodynamically significant congenital heart disease. J Pediatr 2003;143:532-40.

6. Mitchell I, Paes BA, Li A, et al. CARESS: the Canadian registry of palivizumab. Pediatr Infect Dis J 2011;30:651-5.

7. Robinson JL, Le Saux N; Canadian Peadiatric Societylnfectious Disease and Immunization Committee. Preventing hospitalizations for respiratory syncytial virus infection. Paediatr Child Health 2015;20:321-33.

8. Mitchell I, Paes BA, Lanctot K, et al. Letters to the Editor. Paediatr Child Health 2015;20:463-4.

9. Hui C, et al. Palivizumab adherence and outcomes in Canadian Aboriginal children. Pediatr Infect Dis J 2016;35:1187-93.

10. Johnson DW, Adair C, Brant R, et al. Differences in admission rates of children with bronchiolitis by pediatric and general emergency departments. Pediatrics 2002;110:e49.

11. Setting the context: an overview of Aboriginal health in Canada. Prince George (BC): National Collaborating Centre for Aboriginal Health; 2013.
Competing interests: Ian Mitchell has received travel and speaker fees from AbbVie Canada for conference presentations; he has received grants from AbbVie Canada for a respiratory syncytial virus prevention program and an investigator-initiated study. No other competing interests were declared.
This article was solicited and has been peer reviewed.

Contributors: Departments of Paediatrics (Mitchell) and Community Health Sciences (Peiris), Cumming School of Medicine, University of Calgary, Calgary, Alta.
Contributors: Both authors contributed to the conception of the work, drafted and critically revised the manuscript, approved the final version to be published and agreed to act as guarantors of the work.

Correspondence to: Ian Mitchell, imitche@ucalgary.ca 